\title{
Implementing components of the PHC for PE/E model in Nigeria: A cost analysis
}

\author{
Pooja Sripad \\ Population Council \\ Sara Chace Dwyer \\ Population Council \\ Gloria Adoyi \\ Population Council
}

Follow this and additional works at: https://knowledgecommons.popcouncil.org/departments_sbsr-rh

Part of the Demography, Population, and Ecology Commons, Family, Life Course, and Society Commons, International Public Health Commons, Maternal and Child Health Commons, and the Medicine and Health Commons

How does access to this work benefit you? Let us know!

\section{Recommended Citation}

Sripad, Pooja, Sara Chace Dwyer, and Gloria Adoyi. 2019. "Implementing components of the PHC for PE/E model in Nigeria: A cost analysis," Ending Eclampsia Country Brief. Washington, DC: Population Council. 


\section{ENDING Eclampsia}

\section{Implementing Components of the PHC for PE/E Model in Nigeria: A Cost Analysis}

\section{INTRODUCTION}

The maternal mortality rate in Nigeria is 814 per 100,000 live births [1]. Pre-eclampsia and eclampsia (PE/E) is the 4th leading cause of maternal mortality in Nigeria, accounting for $11 \%$ of maternal deaths [2]. PE is identified by high blood pressure and protein in urine within pregnant women after 20 weeks of gestation. Women with PE are at increased risk for organ damage/failure, pre-term birth, loss of pregnancy, and stroke. PE can progress to eclampsia, which is characterized by seizures, and may be associated with kidney and liver damage, as well as maternal death. Infant risks include pre-term birth, low birth weight, stillbirth and death, among others [3]. Infants born preterm due to $P E$ are at higher risk of long term health issues. The risks of $\mathrm{PE} / \mathrm{E}$ can be mitigated with regular screening during antenatal care (ANC) as well as the postnatal period. Once detected, regular monitoring of $\mathrm{PE}$ can lessen progression to severe $\mathrm{PE} / \mathrm{E}$, and even severe $\mathrm{PE} / \mathrm{E}$ can be managed through administration of magnesium sulfate $\left(\mathrm{MgSO}_{4}\right)$ and antihypertensive drugs [3].

Between 2016-2018, the Population Council, in partnership with the Nigerian Federal and State Ministries of Health, implemented an intervention to confront PE/E in three states- Ebonyi, Cross River, and Kogi. This was part of the Ending Eclampsia project, a five-year USAID investment that implemented aspects of the Primary Health Care (PHC) PE/E Model in Bangladesh, Nigeria, and Pakistan.

The intervention in Nigeria was comprised of five components of the PHC for PE/E Model: (1) Task sharing to detect and manage $\mathrm{PE} / \mathrm{E}$ ( $\mathrm{MgSO}_{4}$ and referal) with PHC providers; (2) Introducing antihypertensive drug provision at the PHC level; (3) Engaging women's groups to increase ANC uptake; (4) Logistic Officer training to reduce PE/E commodity stockouts; and (5) Health education messages.

This brief describes the true cost for implementing each component in Nigeria. Full descriptions of the intervention can be found on the Ending Eclampsia website.

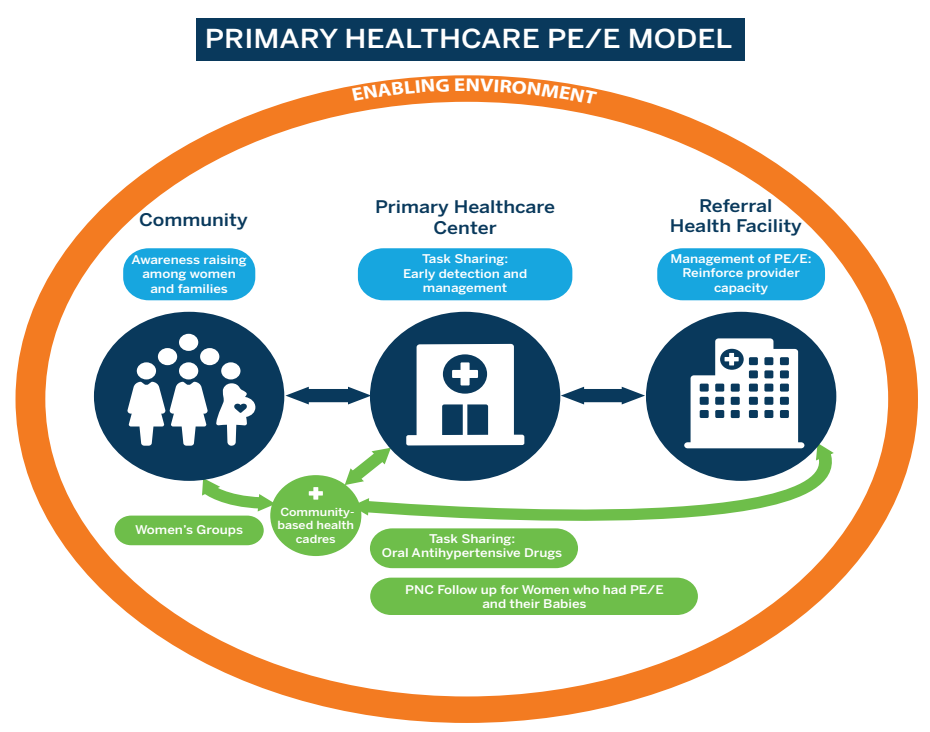

Highlights

- Component 1 Core task sharing to detect and manage PE/E at PHC: 588 providers from 180 facilities across 3 states trained for a total of $\$ 271,909$ and $\$ 462$ per provider trained. Actual cost per provider varied.

- Component 2 Introducing antihypertensive drug provision at PHC: 80 providers trained from 40 facilities across 2 states for a total of $\$ 34,048$ and $\$ 426$ per provider trained.

- Component 3 Engaging women's groups to increase ANC uptake: 48 women leaders trained for a total of $\$ 18,035$ and $\$ 376$ per leader trained.

- Component 4 Logistic officer training: $\mathbf{7 2}$ logistic officers trained for a total of $\$ 15,869$ and $\$ 220$ per officer trained.

- Component 5 Health education messages: 180 providers trained for a total of $\$ 96,446$ and $\$ 536$ per provider.

- Estimates include cost paid by the project, donated by Federal and State ministries of health, and the opportunity costs to participants. Approximately $18 \%$ of total costs were covered by the government and people of Nigeria.

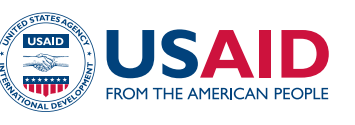

Made possible by the generous support of the American people through the United States Agency for International Development (USAID).
The Population Council conducts research and delivers solutions that improve lives around the world. Big ideas supported by evidence: It's our model for global change. popcouncil.org

(c) 2019 The Population Council, Inc.
POPULATION COUNCIL

Ideas. Evidence. Impact. 


\section{COST ANALYSIS}

The Ending Eclampsia Project in Nigeria collected retrospective cost data between March and May, 2019. A cost ingredient approach was used where each element (input) required to implement activities for the PHC PE/E Model was first identified and then grouped into cost categories: a) personnel, b) supplies, c) infrastructure; d) travel; and (e) miscellaneous. The economic cost of each activity was calculated regardless of whether the project directly paid for the goods or services. For example, to account for the opportunity cost to providers for participating in a training, their daily wage was calculated even though they were not compensated by the project. Project management costs were also captured.

Cost data were collected from the Ending Eclampsia project's budgets and expenditure reports. When cost information was unavailable (e.g. daily rates), average estimates were provided by ministry representatives and from individual state health workers executing the interventions. Based on lessons learned from the project's implementation, additional costs were added in some cases. For example, the number of monitoring visits were standardized across all three states.
Cost data were generally collected in Nigerian Naira in the year purchased. Due to price variations by state, cost data were collected in each state. An average of three states was used to estimate the total cost before being converted into 2018 United States Dollars (USD) using the December 31st closing exchange rate of 363.61 Nigerian Naira (NGN) per 1 USD (XE Currency chart). Program management and office costs were collected in USD and converted to Nigerian Naira where necessary, using the same exchange rate. Costs per participant were calculated for each component.

\section{COMPONENT: 1 CORE TASK SHARING TO THE PHC LEVEL}

Component 1 reflects task-sharing the prevention, detection, and management of PE/E to the PHC level. There were four main activities: (1) training secondary health care providers on the detection and management of PE/E; (2) training $\mathrm{PHC}$ providers on administering a loading dose of $\mathrm{MgSO}_{4}$ and referral; (3) training medical officers managing PHCs on detection and management of PE/E; and (4) routine monitoring support to providers at the facility level.

Table 1 displays the costs to replicate Component 1 task sharing to the PHC level. The total cost was $\$ 271,909$

TABLE 1: Cost of the core task sharing to PHC level component

\begin{tabular}{|l|c|c|c|c|c|}
\hline \multicolumn{1}{|c|}{ Ingredients } & $\begin{array}{c}\text { Cross River } \\
(\text { USD })\end{array}$ & $\begin{array}{c}\text { Ebonyi } \\
(\text { USD })\end{array}$ & $\begin{array}{c}\text { Kogi } \\
(\text { USD })\end{array}$ & Total cost (USD) & $\begin{array}{c}\text { Total cost } \\
(\text { NGN) }\end{array}$ \\
\hline Personnel* & $\$ 52,481$ & $\$ 37,635$ & $\$ 44,922$ & $\$ 138,120$ & $50,221,854$ \\
\hline Supplies & $\$ 910$ & $\$ 686$ & $\$ 783$ & $\$ 2,379$ & 864,988 \\
\hline Infrastructure* & $\$ 16,303$ & $\$ 15,346$ & $\$ 16,693$ & $\$ 49,377$ & $1,795,3893$ \\
\hline Travel & $\$ 38,180$ & $\$ 23,687$ & $\$ 18,231$ & $\$ 80,099$ & $2,9124,640$ \\
\hline Misc. & $\$ 693$ & $\$ 600$ & $\$ 641$ & $\$ 1,934$ & 703,320 \\
\hline Total & $\$ 108,568$ & $\$ 77,955$ & $\$ 81,270$ & $\$ 271,909$ & $98,868,694$ \\
\hline
\end{tabular}

*Total includes overall program management estimates from Abuja

FIGURE 1: Cost per participant for each activity under Component 1 Core task sharing to the PHC level

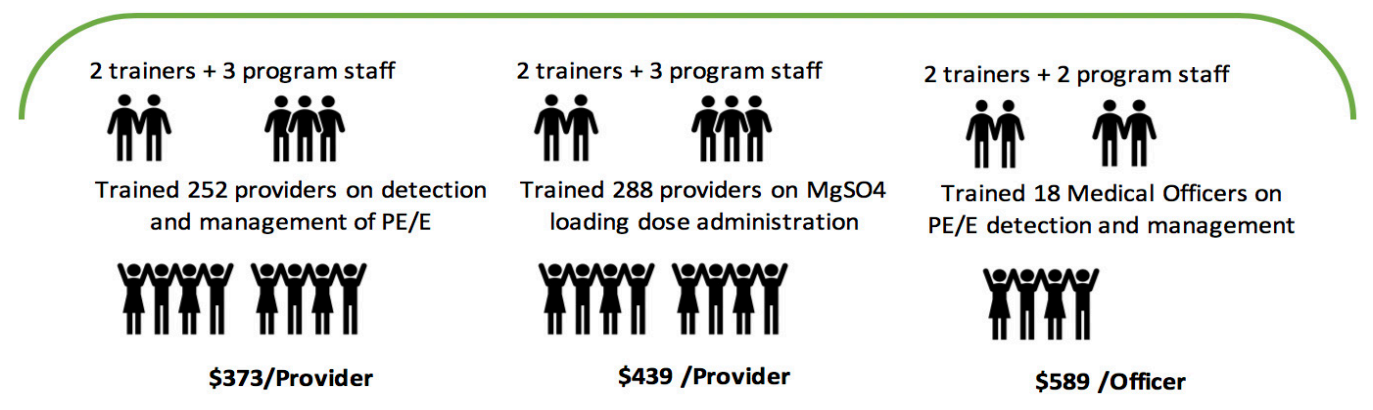

$1 \mathrm{SMoH}+2$ program staff monitored 180 facilities quaterly
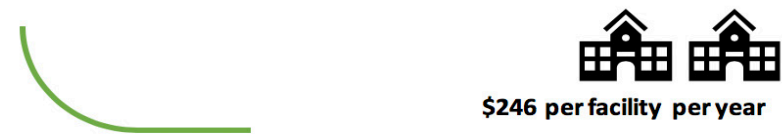

\$246 per facility per year

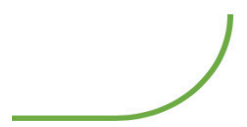


(98,868,694 NGN) with the largest cost categories being personnel, followed by travel and infrastructure. Of the $\$ 138,000$ in personnel costs, approximately $\$ 51,407$ (37\%) were donated in-kind by state ministries of health. Figure 1 shows the cost per participant breakdown. A total of 558 providers from 180 facilities were trained across the three states. For each activity, participants were trained over two days and then participated in a two-day refresher training. Activities were led by certified trainers, program staff, and various federal and state ministry staff. The average cost per provider was $\$ 462$ (168,114 NGN). The cost per provider varied by activity, however. In activity 1, 252 providers from secondary health facilities were trained to detect $\mathrm{PE} / \mathrm{E}$ and administer a loading dose of $\mathrm{MgSO}_{4}$ for an average of $\$ 373$ per provider. For activity 2, 288 providers from primary health facilities were trained in detecting $\mathrm{PE} / \mathrm{E}$ and administering a loading dose of $\mathrm{MgSO}_{4}$ for an average of $\$ 439$ per provider. Eighteen Medical Officers at PHCs from Cross River were trained in early detection and management of $\mathrm{PE} / \mathrm{E}$ for an average of $\$ 589$ per provider. Finally, a team of state ministry of health $(\mathrm{SMoH})$ and Population Council staff conducted quarterly monitoring visits to 180 facilities. The cost per facility was $\$ 246$.
On average, the total cost is Ebonyi were similar to that in Kogi. Overall the total cost in Kogi was $\$ 3,314.71$ more than in Ebonyi. The costs in Cross River were higher than Ebonyi and Kogi because they incorporated the Medical Officer training as well as the state's comparatively more expensive administrative costs.

\section{COMPONENT 2: INTRODUCING ANTIHYPERTENSIVE DRUGS AT PHC}

Ending Eclampsia introduced task sharing the provision of the antihypertensive drug (oral methyldopa) at the PHC level in Ebonyi and Kogi states. This included training providers to counsel their clients on signs of $P E / E$ and to administer antihypertensive drugs. Table 2 shows the total cost for implementing the antihypertensive component in two states. The total cost to implement the antihypertensive component was $\$ 34,048$ (NGN 12,380,122) for an average cost per provider of $\$ 426$ (154,752 NGN). Of the $\$ 17,245$ in personnel costs, $\$ 4,480$ (26\%) were donated in-kind by state ministries of health. Figure 2 shows the cost per provider breakdown. A total of 80 providers from 40 facilities participated in a two-day training. The trainings were conducted by two trainers and three program staff,

TABLE 2: Cost of the introducing antihypertensive at PHC component

\begin{tabular}{|l|c|c|c|c|}
\hline \multicolumn{1}{|c|}{ Ingredients } & Ebonyi (USD) & $\begin{array}{c}\text { Kogi } \\
(\text { USD) }\end{array}$ & Total cost (USD) & $\begin{array}{c}\text { Total cost } \\
(\text { NGN) }\end{array}$ \\
\hline Personnel* & $\$ 7,243$ & $\$ 7,633$ & $\$ 17,246$ & 6270790 \\
\hline Supplies & $\$ 124$ & $\$ 124$ & $\$ 248$ & 90000 \\
\hline Infrastructure* & $\$ 1,576$ & $\$ 1,993$ & $\$ 4,604$ & 1674093 \\
\hline Travel & $\$ 6,108$ & $\$ 5,266$ & $\$ 11,374$ & 4135760 \\
\hline Misc. & $\$ 281$ & $\$ 295$ & $\$ 576$ & 209480 \\
\hline Total & $\$ 15,332$ & $\$ 15,311$ & $\$ 34,048$ & $12,380,122$ \\
\hline
\end{tabular}

*Total includes overall program management estimates from Abuja

FIGURE 2: Cost per participant under Component 2 introducing antihypertensive at PHC

2 trainers +3 program staff

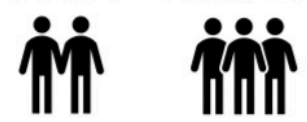

Trained 252 providers on detection and management of $\mathrm{PE} / \mathrm{E}$

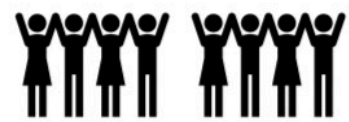

\$241 /provider
$1 \mathrm{SMoH}+2$ program staff

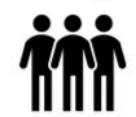

Monitored 40 facilities quaterly

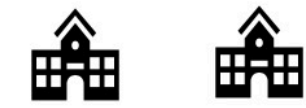

\$189 per facility peryear

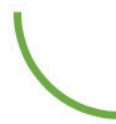


with support from approximately six SMoH staff. The cost per provider was $\$ 241$ (NGN 87,630 ). Forty of the facilities who participated in the antihypertensive component also received monitoring support for antihypertensive administration. This occurred during the same monitoring visits outlined in Component 1 and the costs were shared between the two components. The total cost per facility to monitoring under this component was $\$ 189$ (68,722 NGN).

\section{COMPONENT 3: WOMEN'S GROUPS TO INCREASE ANC UPTAKE}

To encourage uptake of ANC and post-natal care (PNC) services in health facilities in Cross River state, women's group leaders were trained to disseminate health information on ANC and PNC to their peers. They were specifically trained on using pictorial job aids to share health messages with women in their community and a log book to record activities. After the training, they shared health messages during monthly women's group meetings. The women leaders were also provided with mentorship support through a senior nurse appointed by the $\mathrm{SMoH}$.

Table 3 outlines the total costs for implementing the women's group model. The total was $\$ 18,035(6,557,800$ NGN). A total of 48 women leaders were trained at a cost of $\$ 376$ per leader. Trainings were led by a trainer, two program staff, and two SMoH staff. The monitoring visits were conducted by the $\mathrm{SMoH}$ and program staff. On average, each woman leader reached about 250-300 women. State ministries of health and women leaders donated in-kind approximately $\$ 3,905$ of their time and use of community spaces.

TABLE 3: Cost of the women's group component in Cross River

\begin{tabular}{|c|c|c|}
\hline Ingredients & Naira (NGN) & Dollar (USD) \\
\hline Personnel & $2,117,500$ & $\$ 5,824$ \\
\hline Supplies & 54,000 & $\$ 149$ \\
\hline Infrastructure & $1,612,500$ & $\$ 4,435$ \\
\hline Travel & $2,706,000$ & $\$ 7,442$ \\
\hline Misc. & 67,800 & $\$ 186$ \\
\hline Total & $6,557,800$ & $\$ 18,035$ \\
\hline
\end{tabular}

FIGURE 3: Cost per participant under Component 3 women's groups to increase ANC uptake

\section{1 trainers +2 program staff $+2 \mathrm{SMoH}$}

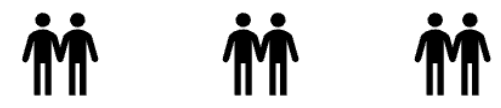

Trained and provided mentorship to 48 providers women's group leaders
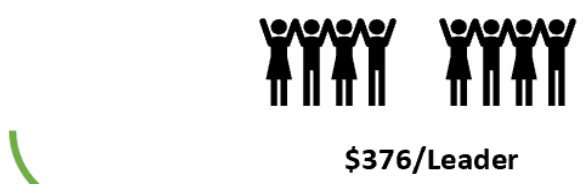

\section{COMPONENT 4: LOGISTIC OFFICER TRAINING}

In implementing Component 1, the Ending Eclampsia team identified communication gaps between health facilities and medical stores. This left facilities without the necessary $\mathrm{MgSO}_{4}$ and oral methyldopa to manage cases of $P E / E$. Seventy-two logistic officers from 36 secondary facilities received additional training on supply chain management. Table 4 details the total cost for Component 4 . The total cost to implement Component 4 was $\$ 15,869$ $(5,036,598 \mathrm{NGN})$ and $\$ 220$ per logistic officer. Of the $\$ 6,179$ personnel costs, $\$ 3,905$ (27\%) were donated inkind by state ministries of health. Figure 4 shows the cost per participant breakdown for the logistic officer trainings.

FIGURE 4: Cost per participant under Component 4 logistic officer training

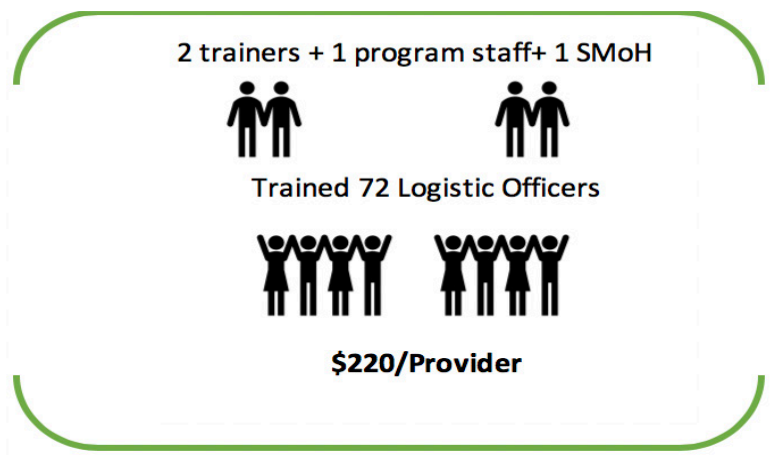

TABLE 4: Cost of the logistic officer training component

\begin{tabular}{|l|c|c|c|c|c|}
\hline \multicolumn{1}{|c|}{ Ingredients } & Cross River (USD) & $\begin{array}{c}\text { Ebonyi } \\
(\text { USD })\end{array}$ & $\begin{array}{c}\text { Kogi } \\
(\text { USD })\end{array}$ & $\begin{array}{c}\text { Total cost } \\
(\text { USD })\end{array}$ & Total cost (NGN) \\
\hline Personnel* & $\$ 1,185$ & $\$ 1,253$ & $\$ 1,372$ & $\$ 6,180$ & $1,887,698$ \\
\hline Supplies & $\$ 0$ & $\$ 0$ & $\$ 0$ & $\$ 0$ & 0 \\
\hline Infrastructure* & $\$ 721$ & $\$ 721$ & $\$ 748$ & $\$ 3,224$ & 796,000 \\
\hline Travel & $\$ 2,178$ & $\$ 2,178$ & $\$ 2,013$ & $\$ 6,369$ & $2,316,000$ \\
\hline Misc. & $\$ 34$ & $\$ 34$ & $\$ 28$ & $\$ 96$ & 36,900 \\
\hline Total & $\$ 4,117$ & $\$ 4,185$ & $\$ 4,162$ & $\$ 15,869$ & $5,036,598$ \\
\hline
\end{tabular}




\section{COMPONENT 5: HEALTH MESSAGES BEFORE ANC}

Component 5 aimed to prepare providers from secondary and primary health facilities to provide PE/E - and related-health educational messages to women - before and during ANC visits. On average, a trainer, three program staff and a $\mathrm{SMoH}$ representative led three trainings, one initial and two refresher trainings, with 180 providers across the three states. As shown in Table 5, the total cost to implement Component 5 was $\$ 96,446(33,809,907$ NGN) with an average cost per participant of $\$ 534$ (187,833 NGN). Of the $\$ 36,805$ in personnel costs, the $\mathrm{SMoH}$ donated inkind approximately $\$ 15,858$ (43\%). The cost to implement this component in Kogi was lower than in the other two states due primarily to lower personnel and travel costs. Figure 5 shows the cost per participant breakdown for Component 5.
FIGURE 5: Cost per participant under Component 5 health messages before ANC

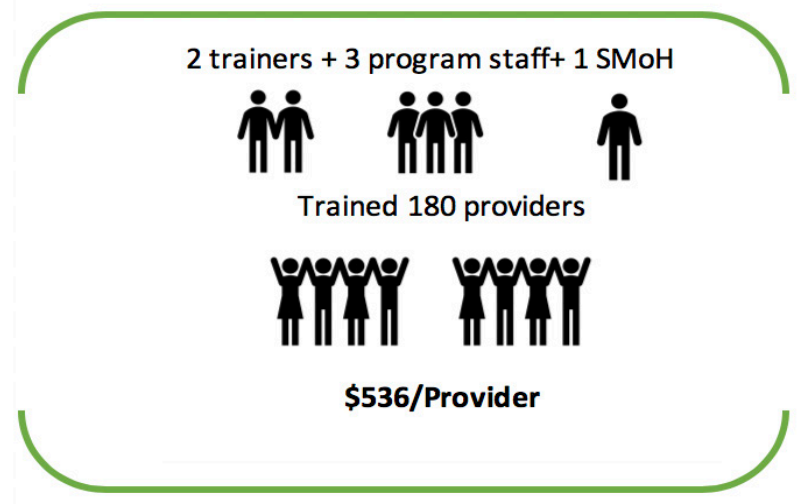

TABLE 5: Cost of the health messages component

\begin{tabular}{|l|c|c|c|c|c|}
\hline \multicolumn{1}{|c|}{ Ingredients } & Cross River (USD) & $\begin{array}{c}\text { Ebonyi } \\
(\text { USD) }\end{array}$ & $\begin{array}{c}\text { Kogi } \\
(\text { USD) }\end{array}$ & $\begin{array}{c}\text { Total cost } \\
(\text { USD) }\end{array}$ & Total cost (NGN) \\
\hline Personnel* & $\$ 10,437$ & $\$ 13,554$ & $\$ 10,444$ & $\$ 36,806$ & $12,521,107$ \\
\hline Supplies & $\$ 201$ & $\$ 201$ & $\$ 189$ & $\$ 591$ & 214,800 \\
\hline Infrastructure* & $\$ 5,394$ & $\$ 7,239$ & $\$ 5,459$ & $\$ 19,126$ & $6,578,200$ \\
\hline Travel & $\$ 18,771$ & $\$ 11,002$ & $\$ 9,638$ & $\$ 39,412$ & $14,339,500$ \\
\hline Misc. & $\$ 171$ & $\$ 171$ & $\$ 171$ & $\$ 512$ & 156,300 \\
\hline Total & $\$ 34,974$ & $\$ 32,167$ & $\$ 25,901$ & $\$ 96,447$ & $33,809,907$ \\
\hline
\end{tabular}

*Total includes overall program management estimates from Abuja

\section{CONCLUSION}

The total direct cost to implement the Ending Eclampsia project activities in Nigeria was \$436,307 (156,653,121 NGN). Across all components, personnel and travel comprised the largest costs categories, accounting for approximately $47 \%$ and $33 \%$ of the total cost respectively. Personnel was the largest cost component because this was a human resource-based intervention. The project directly paid for approximately $80 \%$ of the personnel costs captured here, however it was important to capture the true costs for the participants' contribution to the project. By participating in the project, providers were taken away from their health facilities, $\mathrm{SMoH}$ staff were unable to partake in other health interventions, and women leaders were diverted from other life and/or income generating activities. This analysis, therefore, captured the opportunity costs to providers, SMoH staff, and women leaders.

Travel costs were high because the project was implemented across three states and managed by the Ending Eclampsia project based in Abuja. This required program staff and trainers to travel frequently, incurring high airfare costs. Although there were additional travel costs, the staff in Abuja ensured the activities were implemented with high quality in each state. Costs could be reduced by hiring in-state program staff, but additional costs for quality assurance would be required.

Considering the implementation of the PHC-PE/E Model was phased in state by state and progressively added components according to an implementation research approach that tested the feasibility of PHC providers' ability to manage $\mathrm{PE} / \mathrm{E}$ to varying degrees, costs could be saved for future implementers. For example, if trainings on antihypertensives and ANC messages were incorporated into the core task-sharing component initially, implementation costs would be shared and likely reduced. Similarly implementing the logistics officer training and women leaders trainings concurrently with Component One workshops would have reduced on travel expenditures. 
To replicate this intervention, infrastructure and travel costs may vary depending on whether the implementing organization or agency already purchased large equipment and could share the cost across other activities (i.e. vehicles and projectors), or would need to rent these goods and services. Average rental costs were used for this analysis to provider a broader synapsis of the cost, although the cost to the project may have been lower.

This implementation cost analysis serves as a starting point for those considering implementation of different components of the PHC PE/E Model. Ways to consolidate costs of implementing the five components of the Nigeria Ending Eclampsia intervention should be explored. Future work could also explore integrating the five components into existing training mechanisms for PHC providers and how to support community groups to disseminate health messages.

\section{REFERENCES}

1. World Bank Group. WHO, UNICEF, UNFPA, World Bank Group, and the United Nations Population Division. Trends in Maternal Mortality: 1990 to 2015. Geneva, World Health Organization, 2015. World Bank Open Data. https://data.worldbank.org/

2. Frederick Wekesah, Chiamaraoke Izubara. 2017 "Maternal Health in Nigeria: Facts and Figures." Kenya: Africa Population and Health Research Center.

3. World Health Organization. Integrated Management of Pregnancy and Childbirth (IMPAC). https://www.who.int/ maternal_child_adolescent/topics/maternal/impac/en/

\section{CONTACT}

Pooja Sripad, Associate, Population Council psripad@popcouncil.org

Sara Chace Dwyer, Staff Associate, Population Council schace@popcouncil.org

Gloria Adoyi, Program Officer, Population Council gadoyi@popcouncil.org 